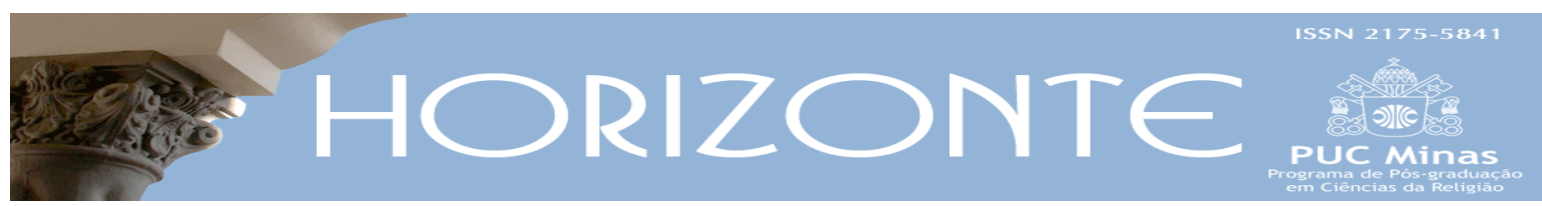

Dossiê: Fundamentalismos e Democracia - Temática Livre (C) (1)

\title{
As relações interdisciplinares em Ciências das Religiões
}

\author{
The interdisciplinary relations in Sciences of Religions
}

\author{
Elisa Pereira Gonsalves Possebon* \\ Fabricio Possebon $^{* *}$
}

\begin{abstract}
Resumo
O artigo apresenta uma reflexão, no ambiente acadêmico, sobre as relações interdisciplinares, que são distintas da disciplinaridade e da multidisciplinaridade, estas já bem sedimentadas. Para tanto, compreende a disciplina como um campo específico de conhecimento, em termos teóricos e metodológicos, situando a interdisciplinaridade como uma resposta às limitações impostas pela especialização disciplinar. A partir de uma metodologia que utiliza a revisão bibliográfica como elemento central, conclui que a vocação do campo de conhecimento das Ciências das Religiões para a interdisciplinaridade se dá pela disposição e possibilidade teórica e organizacional de pesquisadores, de diferentes áreas de conhecimento, compartilharem de um mesmo espaço acadêmico. Destaca a identidade das Ciências das Religiões, enquanto disciplina, e remete para a importância de diálogos interdisciplinares para a produção de novos conhecimentos. Recorda finalmente o trabalho pioneiro de Max Muller, considerado um dos fundadores da área de Ciências das Religiões, cujo método por ele proposto, chamado filológico, dá pistas para a aplicação do conceito de interdisciplinaridade.
\end{abstract}

Palavras-chave: Interdisciplinaridade. Projetos interdisciplinares. Ciências das Religiões.

\begin{abstract}
The article presents a reflection, in the academic environment, on interdisciplinary relations, which are distinct from disciplinarity and multidisciplinarity, these already well established. To do so, it understands the discipline as a specific field of knowledge in theoretical and methodological terms, placing interdisciplinarity as a response to the limitations imposed by disciplinary specialization. Based on a methodology that uses the bibliographic review as a central element, it concludes that the vocation of the field of knowledge of the Sciences of Religions for interdisciplinarity is given by the theoretical and organizational disposition and possibility of researchers, from different areas of knowledge, to share a same academic space. It highlights the identity of the Sciences of Religions as a discipline, and refers to the importance of interdisciplinary dialogues for the production of new knowledge. Finally it recalls the pioneering work of Max Muller, considered one of the founders of the area of Sciences of Religions, whose method he proposed, called philological, gives clues to the application of the concept of interdisciplinarity.
\end{abstract}

Keywords: Interdisciplinarity. Interdisciplinary projects. Sciences of Religions.

Artigo submetido em 16 de maio de 2019 e aprovado em 11 de dezembro de 2020.

* Doutora em Educação pela Universidade Metodista de Piracicaba, Professora Titular do Centro de Educação da UFPB. País de origem: Brasil. E-mail: elisa.gonsalves@gmail.com

*** Doutor em Letras pela UFPB. Professor do Centro de Educação da UFPB. País de origem: Brasil. E-mail: fabriciopossebon@gmail.com 


\section{Introdução}

A interdisciplinaridade é tema marcante nos meios acadêmicos, configurando-se como um desafio que perpassa todas as áreas de conhecimento. Este artigo tem como objetivo descrever os principais elementos que caracterizam a prática acadêmica interdisciplinar, atentando para a constituição das Ciências das Religiões $^{1}$ como um campo de conhecimento propício para o desenvolvimento de projetos desta natureza. Para tanto, trata da especificidade do trabalho interdisciplinar, destacando os desafios para a construção de sujeitos e espaços propícios para o estabelecimento de relações interdisciplinares.

Para compor sua argumentação, o texto está organizado em cinco partes: a distinção entre pluri, multi, trans e disciplinaridade; a natureza das relações interdisciplinares; sujeitos e espaços interdisciplinares; projetos interdisciplinares; e, por fim, um olhar sobre o tema em Ciências das Religiões, recordando o trabalho de um dos pioneiros da área.

\section{A distinção entre pluri, multi, trans e disciplinaridade}

Compreender a natureza do que está entre as disciplinas, isto é, compreender a interdisciplinaridade, pressupõe o entendimento do que seja disciplinar. Somente a partir de uma profunda reflexão sobre o que constitui uma disciplina é que podemos avançar no sentido de pensar formas de interação e diálogo entre elas.

A disciplina remete para uma identidade, um conjunto orgânico e homogêneo de conhecimentos que tem como objetivo produzir, a partir de métodos próprios, novos saberes sobre o tema que lhe é pertinente. Apesar dos seus limites

\footnotetext{
${ }^{1}$ Sobre o emprego destes termos, quer no singular quer no plural, dissemos: "Quanto ao nome do curso, não foi utilizado "Ciência(s) da Religião" porque o singular tende a pressupor a existência de um método científico e de um objeto unitário. Entretanto, quem prefere falar de "Ciências das Religiões" o faz porque está convencido tanto do pluralismo metodológico quanto do pluralismo do objeto. Esta foi nossa opção filosófica". Texto extraído de "Ciências das Religiões: proposta pluralista na UFPB", escrito por Miele; Fabricio (2012, p. 420).
} 
não serem absolutamente delimitados em sua especificidade, podemos destacar, inspirados nos estudos apresentados por Pombo, Guimarães e Levy (2006), critérios que delimitam um campo disciplinar, que se faz a partir de contingências históricas:

a) domínio material: corresponde a um conjunto de objetos aos quais, por estarem agregados, tornam-se matéria própria de um campo de conhecimento. Algumas disciplinas se sobrepõem neste ponto por se ocuparem de um mesmo conjunto de objeto, apesar de terem enfoques diferentes a partir de suas especificidades;

b) integração teórica: refere-se aos conceitos principais que alicerçam e unificam teoricamente o campo de conhecimento. Constituindo-se como pilares que estruturam, integram e dão coerência interna à disciplina, este critério revela a maturidade do campo e sua fertilidade, no sentido de compreender os fenômenos do seu domínio.

c) métodos de coleta e análise próprios: a consolidação de uma disciplina está na dependência da criação e aperfeiçoamento de métodos próprios de investigação. Neste sentido, o aprofundamento da compreensão do objeto pode remeter para novas possibilidades de apreensão e transformação dos fenômenos.

d) aplicações: corresponde à capacidade de estar orientada para a aplicação e utilização prática dos conhecimentos adquiridos em um determinado campo profissional.

Considerando os aspectos citados podemos afirmar que cada disciplina, por exemplo, a física, a sociologia, a biologia, etc., possui um corpus teórico e metodológico específico e que "representa e possui uma forma de conhecimento, baseada em um método próprio, que deve ser respeitada e valorizada" (SOBRAL; SAMPAIO; FERNANDES; PHILIPPI JÚNIOR, 2015, p. 518).

Podemos afirmar que a disciplinaridade 
É o conjunto de conhecimentos que tem objeto próprio, aparato conceitual, sistema teórico, conceitos lógicos, linguagem própria e finalidades. Cada disciplina atua em um campo específico do conhecimento estabelecendo as fronteiras da produção do conhecimento que lhe corresponde. A disciplina possui uma abordagem circunscrita do real em torno de seu objeto científico, de maneira que sua área de ação deve ser precisamente definida. (FARIA, 2015, p. 104).

Neste momento, cabe ainda esclarecer a distinção entre os termos pluridisciplinaridade, multidisciplinaridade e transdisciplinaridade.

A pluridisciplinaridade corresponde ao estudo de um objeto por diferentes disciplinas ao mesmo tempo, sem que exista a prevalência de alguma, já que cada uma faz uso do seu próprio domínio, em seu próprio espaço. Neste sentido, apesar da existência de um objeto comum, as teorias, métodos, procedimentos e interpretações são disciplinares, resultando em um coletivo formado sob a lógica "todos juntos, mas cada um por si" (FARIA, 2015, p. 105).

Isto ocorre, por exemplo, quando um fenômeno é estudado pela Psicologia, Educação, História, Sociologia, Psiquiatria e Estatística, como é o caso da violência contra a mulher. Diferentes campos de conhecimento podem estudar o mesmo objeto a partir de suas matrizes analíticas e de seus procedimentos metodológicos, com uma interlocução entre os diferentes campos. "Todos juntos" estudando o mesmo fenômeno, "mas cada um por si”, a partir de seu domínio, sem interações.

Por sua vez, a multidisciplinaridade consiste no exame de um objeto estudado simultaneamente por várias disciplinas, que dialogam entre si. Cada disciplina mantém sua especificidade teórica e metodológica, obtendo resultados distintos e não integrados, porém, a possibilidade de intercâmbios é real já que os pesquisadores "compartilham do objeto, das discussões, das análises e interpretações, mas a versão que produzirão terá um caráter disciplinar ampliado”. (FARIA, 2015, p. 105).

Podemos afirmar que a multidisciplinaridade é um passo adiante da pluridisciplinaridade, pois apesar da feitura do trabalho investigativo ser de caráter disciplinar, existe a possibilidade de compartilhamentos. A multidisciplinaridade é 
muito comum em eventos científicos que, para debater um determinado tema, convidam três especialistas de disciplinas distintas, que possam dialogar ente si, a partir de suas bases conceituais.

A transdisciplinaridade corresponde a uma forma de pesquisa que está para além das disciplinas, configurando-se como uma "metadisciplina que aspira articular níveis de realidade com o pressuposto de contemplar diferentes lógicas em uma estrutura complexa” (FARIA, 2015, p. 105). É considerada uma etapa superior à interdisciplinaridade porque não atinge apenas interações, mas impõe uma nova concepção de fazer científico, articulada com a noção de complexidade.

A seguir, aprofundaremos a questão da interdisciplinaridade, eixo central deste artigo, buscando compreender sua possibilidade no campo das Ciências das Religiões.

\title{
2 A natureza das relações interdisciplinares
}

A interdisciplinaridade supõe a existência e a afirmação das disciplinas, é "pressuposto da interdisciplinaridade o conhecimento disciplinar sólido, sem o qual não há como desenvolver projetos de pesquisa interdisciplinares de qualidade.” (SOBRAL, SAMPAIO, FERNANDES; PHILIPPI JÚNIOR, 2015, p. 517).

Nesses termos, a interdisciplinaridade significa um salto de qualidade:

\begin{abstract}
Não pode haver interdisciplinaridade sem a contribuição das disciplinas. Não se trata, portanto, de superar as disciplinas, mas de ultrapassar a visão disciplinar em uma mesma teoria integradora. Dito de outra forma, a análise interdisciplinar trabalha com as disciplinas, respeitadas suas diferenças, para alcançar uma dimensão teórica integradora. Isso significa que a interdisciplinaridade deve contemplar a diversidade para obter a unidade. (FARIA, 2015, p. 134).
\end{abstract}

A interdisciplinaridade nasce como uma reação às limitações impostas pela especialização, pelo reducionismo científico, que condenaram a ciência a uma compreensão restrita e fragmentada dos objetos científicos. O estudo das relações interdisciplinares está relacionado à "necessidade de se dar conta de novos 
problemas, de diferentes naturezas e com níveis de complexidade crescentes, muitas vezes decorrentes do próprio avanço dos conhecimentos científicos, filosóficos e tecnológicos." (FARIA, 2015, p. 107).

Em termos institucionais, cabe fazer o registro do avanço obtido no âmbito do trabalho interdisciplinar quando foi criada, em 1999, na Coordenação de Aperfeiçoamento de Pessoal de Nível Superior (CAPES), a Área Multidisciplinar. Em 2008, em substituição a esta Área foi criada a Área Interdisciplinar, que historicamente pode ser configurada como um marco histórico impulsionador de pesquisas nesta área, como também um importante elemento desafiador para as outras áreas. Cabe destacar que no ano de 2011 foi publicada a obra inspiradora Interdisciplinaridade em ciência, tecnologia e inovação, sob a direção de Arlindo Philippi Júnior e António J. Silva Neto, em comemoração aos 10 anos de existência da Área Interdisciplinar. A interdisciplinaridade, enquanto uma racionalidade mais ampla, permitiu a instauração de processos de conhecimento, a nível nacional, baseados no diálogo entre as ciências naturais, sociais e humanidades, o que se denominou de "verdadeira interdisciplinaridade" ou de "interdisciplinaridade ampla." (SOMMERMAN, 2014, p. 58-61).

A interdisciplinaridade surge como uma resposta possível do próprio desenvolvimento científico, pela convicção de que conhecimentos estanques e compartimentados mostraram-se insuficientes para resolver novos problemas colocados na contemporaneidade. Este desenvolvimento permitiu a emergência de novas ciências como bioquímica, sociolinguística, dentre outras (ARANA et al, 2016).

O princípio básico da interdisciplinaridade está relacionado com a proposta da (re)ligação dos saberes, que observa as fronteiras disciplinares não apenas para trazer diálogos e trocas teóricas e metodológicas mas, sobretudo, para constituir uma nova forma de produção do conhecimento (ALVARENGA; ALVAREZ; SOMMERMAN; PHILIPPI JÚNIOR, 2015). 
Cabe destacar neste momento que se a interdisciplinaridade se constitui como uma exigência interna de diferentes disciplinas para dar uma resposta conjunta a um novo problema, ela também se configura como o elemento seminal da transdisciplinaridade. Não mais mantidos limites que determinam de forma absoluta as disciplinas e tornados insuficientes os mecanismos dialogais entre elas na promoção de uma resposta frente às necessidades, emerge a perspectiva transdisciplinar, que dá um passo adiante e afirma a não separabilidade enquanto conceito central. A ideia de diálogo entre disciplinas é substituída pela interação, pela unidade das coisas. O reconhecimento de que o mundo é indivisível é uma virada epistemológica e ontológica que traz consequências para o fazer metodológico científico.

A interdisciplinaridade pode ser compreendia como uma exigência interna das ciências. Isto ocorre porque uma disciplina particular pode ser entendida apenas como um nível da ciência, organizado para observar, descrever e explicar um fenômeno sob um determinado prisma; no entanto, o fenômeno é múltiplo e não se reduz a uma disciplina. Trata-se da "articulação compartilhada de abordagens próprias das disciplinas", marcada pela "primazia do objeto e não da teoria, pelo primado da realidade e não da ideia" (FARIA 2015, p. 107). Neste sentido, a interdisciplinaridade está relacionada com o esforço de restituir, na ciência, a dinâmica própria do objeto investigado.

Estar atento às conexões diversas existentes no fenômeno é o grande desafio da interdisciplinaridade. Tais conexões podem ser identificadas mediante processos de co-ocorrências entre as disciplinas que, ao lançarem olhares para um determinado fenômeno, exigem uma resposta para além de uma perspectiva disciplinar. Neste sentido, a interdisciplinaridade se apresenta "como um modo de organização e articulação de saberes disciplinares na prática da pesquisa, nutrindose delas sem dissolvê-las, especialmente quando a solução de um problema de pesquisa é invisível no âmbito de uma única disciplina." (FARIA, 2015, p. 106). 
Este desafio remete para a correlação entre disciplinas quando elas se vinculam para alcançar um determinado objetivo, ultrapassando o formalismo das relações diplomáticas entre disciplinas para instituir a cooperação orgânica entre pesquisadores, para construir uma verdadeira filosofia de trabalho orientadora de novas formas de pensar e de fazer ciência. Daí a afirmação de que a “interdisciplinaridade expressa, no domínio acadêmico, os problemas da vinculação comunicativa e informacional.” (GOMEZ, 2016, p. 3).

O âmago da discussão sobre interdisciplinaridade está centrado, pois, na noção de relação e de diálogo. Neste sentido, é importante retomar os elementos essenciais do agir comunicativo, que envolve competência para saber falar e saber escutar:

No processo da fala e da escuta, a disciplina do silêncio a ser assumida com rigor e a seu tempo pelos sujeitos que falam e escutam é um sine qua da comunicação dialógica. O primeiro sinal de que o sujeito que fala sabe escutar é a demonstração de sua capacidade de controlar não só a necessidade de dizer a sua palavra, que é um direito, mas também o gosto pessoal, profundamente respeitável, de expressá-la. Quem tem o que dizer tem igualmente o direito e o dever de dizê-lo. É preciso, porém, que quem tem o que dizer saiba, sem sombra de dúvida, não ser o único ou a única a ter o que dizer. Mais ainda, que o que tem a dizer não é necessariamente, por mais importante que seja, a verdade alvissareira por todos esperada. (FREIRE, 2018, p. 114).

Neste sentido, as competências emocionais e de comunicação do pesquisador são fundamentais para a construção de grupos interdisciplinares e elas advêm não apenas da maturidade profissional e científica, mas também de aspectos de ordem pessoal. Assim, não se pode esquecer que a referência ao trabalho interdisciplinar corresponde a uma forma de retratar o esforço humano de transformar o mundo e a natureza, e que este esforço possui elementos objetivos e subjetivos que envolvem a humanidade do próprio pesquisador. Os saberes dialogam entre si, eles dialogam através de indivíduos que se comunicam.

De acordo com Sommerman (2015, p. 209), o próprio objeto da interdisciplinaridade está centrado nos "saberes das disciplinas das quatro grandes áreas do conhecimento acadêmico - ciências da natureza, ciências formais, ciências 
sociais e humanidades". Isto significa que a ideia de relação remete para a unidade do conhecimento, para um trânsito entre as grandes áreas do conhecimento e não apenas para uma colaboração no interior de uma área.

Nesses temos, a relação própria da interdisciplinaridade

exige não só diálogos entre disciplinas próximas, dentro da mesma área do conhecimento, mas também diálogos entre disciplinas de áreas diferentes, como uma interação entre os saberes disciplinares, e entre estes e os não disciplinares oriundos da sociedade, das relações de produção das condições materiais de existência e das culturas. (FARIA, 2015, p. 107).

A interdisciplinaridade é uma experiência de transcendência do cientista que supera a sua própria especialidade, tomando ciência dos seus próprios limites, identificando as necessidades de diálogos com outras disciplinas. Pela sua complexidade, ela remete para desafios de ordem pedagógica na atividade curricular, afetando objetivos, conteúdos, metodologias e formas de avaliação, além de possibilitar a abertura de novas linhas de pesquisa. Nesses termos, a interdisciplinaridade

promove sínteses capazes de aproximar áreas e setores que se julgavam alheios ao objeto de estudo, gera avanços cognitivos qualitativos e induz a adoção de novas modalidades de produção e compartilhamento de conhecimento. (NEVES, 2015, p. 497).

Uma definição do conceito de interdisciplinaridade pode ser apresentada como

Interação prolongada e coordenada entre disciplinas acadêmicas, para a resolução de determinado problema complexo que não pode ser resolvido por abordagens monodisciplinares, levando a:

- Integração dos diferentes discursos.

- Criação de uma terminologia comum ou um quadro conceitual comum (formando pontes entre as disciplinas).

- Formulação de uma metodologia comum, transcendendo ou na interface das epistemologias de diferentes disciplinas.

- Geração de um conhecimento novo. (SOMMERMAN, 2015, p. 208).

A investigação interdisciplinar é orientada para a escuta sensível do fenômeno, pois é ele quem vai coordenar todo o processo de produção do 
conhecimento e não a lógica disciplinar. Há um elemento epistemológico diferenciado que rompe com o paradigma tradicional, instaurando uma criticidade capaz de reconhecer a complexidade do fenômeno, que está para além do caráter disciplinar.

De acordo com Faria (2015),

O objeto não possui uma disciplina, ainda que ela possua um objeto. Dessa maneira, o olhar dirigido ao objeto é sempre e necessariamente condicionado por ele e por suas inúmeras relações, sua complexidade e suas contradições. Por exemplo, ao estudar um movimento social que luta pelo desenvolvimento sustentável de seu território, é necessário considerar a perspectiva da política (pública), da sociologia, da economia, da gestão, da psicologia social, da história, da antropologia (...) Todos esses fatores encontram-se ao mesmo tempo no mesmo objeto de estudo. $\mathrm{O}$ olhar disciplinar separa cada parte do problema conforme a disciplina. O multidisciplinar e o pluridisciplinar colocam cada parte do problema lado a lado para, a partir de uma discussão, poder agrupar as diversas concepções. $\mathrm{O}$ interdisciplinar considera que a compreensão do objeto demanda os olhares de todas as disciplinas simultaneamente, pois entende que todas se relacionam, ou seja, que são aspectos de um mesmo fenômeno. (FARIA, 2015, p. 109).

E aqui reafirmamos uma ideia no debate interdisciplinar: o fenômeno é reconhecido como complexo e que, para ser desvelado, necessita ser estudado simultaneamente por diferentes disciplinas que, por sua vez, precisam instaurar diálogos críticos e criativos para apreendê-lo, posto que as lógicas disciplinares não podem acessá-lo.

\section{Sujeitos e espaços interdisciplinares}

A constituição da equipe interdisciplinar envolve um conjunto de exigências próprias da existência de equipes heterogêneas, com profissionais com larga experiência em seu campo de pesquisa, e que se colocam corajosamente diante de novos desafios epistêmicos.

De acordo com Durham, Setúbal e Barrera (2015), as iniciativas apontam para formas diferentes de relações interdisciplinares, que coexistem e podem ser agrupadas em três blocos: 
- Cooperação entre grupos distintos de cientistas que atuam na área de exatas e em uma área de aplicação (isto é, uma área de ciência quantitativa emergente).

. Inclusão de cientistas da área de exatas em um grupo de cientistas de uma área de aplicação.

. Criação de grupos híbridos de cientistas de exatas e de uma área de aplicação, cujo objetivo central é a evolução na área de aplicação. (DURHAM, SETÚBAL; BARRERA, 2015, p. 636).

As três possibilidades acima descritas pelos autores citados indicam a constituição emergente de uma área de conhecimento como a bioinformática, a incorporação de pesquisadores da área de exatas em diferentes áreas de aplicação, até a organização de grupos hídricos, realidade ainda não tão comum no Brasil.

A presença de pesquisadores de diferentes disciplinas em um espaço de pesquisa implica, necessariamente, no reconhecimento e no respeito das suas abordagens, posto que "colaboração não significa homogeneização" (RAYNAUT, 2015, p. 541). Somente uma atitude de respeito aos saberes de diferentes disciplinas é que permitirá a construção de "noções integradoras", o cerne do trabalho interdisciplinar. As noções integradoras constituem o núcleo fértil dos espaços de intersecção de onde serão originadas as problemáticas interdisciplinares (RAYNAUT, 2015).

A partir do momento em que as questões da pesquisa forem identificadas através de um exercício dialógico e consensual entre os pesquisadores, é preciso elaborar metodologias criativas que contemplem as contribuições das diferentes disciplinas (RAYNAUT, 2015, p. 541).

A operacionalização de um trabalho interdisciplinar traz como exigência um cuidado redobrado com a questão metodológica. Ela é de grande complexidade requer um conjunto de habilidades e de amadurecimento dos pesquisadores, sobretudo porque sua tendência praticamente inevitável é a da criação de novas estratégicas metodológicas para abordar o fenômeno de forma crítica e criativa. 
Cabe, neste momento, destacar a importância da criação de novos espaços institucionais que possam abarcar as iniciativas interdisciplinares.

Durham, Setúbal e Barrera (2015) sublinham que a emergência e a consolidação de novas iniciativas interdisciplinares estão na dependência da criação de estruturas horizontais nas universidades. Os autores destacam como exemplo bem-sucedido os programas de pós-graduação interunidades e os núcleos de apoio à pesquisa da USP, que agregam professores de diferentes departamentos. A análise do que ocorre na USP permitiu aos autores afirmarem que, quando se trata do fortalecimento da interdisciplinaridade, há uma anterioridade dos núcleos com relação aos programas, pois compete a eles "amadurecer o conhecimento sobre as necessidades específicas de formação de quadros para a problemática interdisciplinar sendo tratada, inclusive avaliando-se se existe a necessidade de um programa de pós-graduação específico." (DURHAM, SETÚBAL; BARRERA, 2015, p. 638).

Os núcleos, como unidades administrativas mínimas, têm a capacidade de serem mais flexíveis e dinâmicos em termos de gestão e de realização dos trabalhos. Além disso,

possibilitam a criação de uma identidade a novos tópicos interdisciplinares, que é importante para a agregação de talentos de várias áreas, e também a criação de pequenas estruturas administrativas para o gerenciamento de projetos comuns, envolvendo docentes de unidades diferentes sem o peso da criação de institutos independentes. (DURHAM, SETÚBAL; BARRERA, 2015, p. 638).

Um elemento importante que merece ainda ser destacado está relacionado com a questão da convivência entre os pesquisadores. O cotidiano possui muitos entraves burocráticos e administrativos, além de uma carga horária muitas vezes excessiva, o que limita os espaços de interlocução entre os pesquisadores. É preciso expandir esta possibilidade para além de eventos, grupos de trabalhos e/ou bancas examinadoras. Os pesquisadores precisam se encontrar. De acordo com Durham, Setúbal e Barrera (2015, p. 640) a "universidade precisa promover espaços de 
convivência de pesquisadores de várias áreas que permitam um contato mais frequente entre estes".

Neste sentido, há de se expandir a noção de encontro para além de

conferências, mesas e bancas. É preciso encontrar o outro para reconhecer nele o que pode me mover. Há de se criar espaços de convivência com mais liberdade e menos burocracia, para que os pesquisadores possam estabelecer diálogos e exercitar a escuta sem que isto se configure como um ritual acadêmico instituído burocratizado.

\section{Projetos interdisciplinares}

Uma proposta interdisciplinar está na dependência da construção de um objeto de estudo que contemple sua natureza intrínseca. Este é o primeiro passo: o de articular uma questão de pesquisa a partir dos diferentes "saberes das disciplinas das quatro áreas do conhecimento acadêmico - ciências da natureza, ciências formais, ciências sociais e humanidades.” (SOMMERMAN, 2015, p. 209). Esta articulação é necessária quando a questão da investigação não pode ser resolvida através de uma abordagem disciplinar, multidisciplinar ou pluridisciplinar: o fenômeno a ser investigado tem uma identidade múltipla, só pode ser conhecido mediante a superação de posturas fragmentadas.

É importante considerar que a questão da integração entre disciplinas não se dá de uma única forma. Ela se realiza em fases que, ao serem vivenciadas, permitem um trânsito mais aprofundado. Ortega Martinez et al (2014, p. 176-177) destacam três fases do processo de integração:

a. Integração para si: corresponde à sensibilização individual, relacionando-se à tomada de consciência pessoal da necessidade real e objetiva de integração.

b. Integração em si: diz respeito ao trabalho coletivo de investigação, especialmente no que se refere ao trabalho metodológico. Também está relacionado com os desafios da integração conceitual e procedimental. 
c. Integração na prática: refere-se à materialização do trabalho integrador. Neste momento a dinâmica da integração é realizada mediante aprofundamentos e geração de novos conhecimentos, habilidades e valores sobre o trabalho que se realiza de forma sistêmica e sistemática.

Dos estudos acerca da consolidação de projetos interdisciplinares é possível destacar quatro importantes lições:

. Lição 1: interdisciplinaridade implica o reconhecimento e o respeito da diversidade das abordagens disciplinares. Colaboração não significa homogeneização.

- Lição 2: respeitar a diversidade não impede de achar pontos de convergência e noções integradoras que viabilizarão a articulação das contribuições.

- Lição 3: a elaboração de uma problemática comum - constituída por um encadeamento de hipóteses que fazem sentido para todos - fornece a "coluna vertebral" que permitirá a convergência e a articulação das contribuições disciplinares.

. Lição 4: uma problemática comum não representa um obstáculo para as problemáticas disciplinares, mas sim o espaço de intersecção entre essas problemáticas específicas, que serão elaboradas conforme as preocupações teóricas de cada disciplina. (RAYNAUT, 2015, p. 541).

Se até então os estudos disciplinares podem ser compreendidos como simples, de fato por estarmos mais familiarizados com seus aportes teóricos e métodos, os trabalhos interdisciplinares têm como ponto de partida "construir um entendimento e um domínio linguístico comum sobre a temática do objeto de estudo.” (SOBRAL, SAMPAIO, FERNANDES; PHILIPPI JÚNIOR, 2015, p. 517). Além disso, a interdisciplinaridade

é entendia como uma das formas de relevância para alcançar patamares mais elevados de inovação. A inovação acaba por acontecer quando diferentes perspectivas se somam e revelam mais nuanças do fenômeno estudado do que a mera soma de perspectivas. Com base nessas características, a interdisciplinaridade passa a ser identificada como uma necessidade das ciências modernas. (SOBRAL; SAMPAIO; FERNANDES; PHILIPPI JÚNIOR, 2015, p. 519). 
A elaboração de projetos de pesquisa interdisciplinares exige mais tempo, não apenas no processo de elaboração, mas especialmente no processo de obtenção de respostas tendo em vista que

\begin{abstract}
pressupõe a necessidade de mais discussão, mais diálogo e, principalmente, a definição de estágios de como levar o resultado à comunidade científica em uma linguagem comum aos participantes do trabalho, contribuindo para o melhor entendimento dos textos produzidos e sua aceitação em periódicos de qualidade. É o caminho dos pioneiros. (SOBRAL; SAMPAIO; FERNANDES; PHILIPPI JÚNIOR, 2015, p. 518).
\end{abstract}

Por fim, cabe destacar que se o elemento essencial da interdisciplinaridade, posto historicamente, é o da existência e reconhecimento das fontes disciplinares, isto não constitui a construção de um conjunto de "supercientistas" que irão produzir uma "superciência". No entanto, é fundamental a compreensão de que falar de trabalho interdisciplinar é falar de indivíduos que realizam o trabalho, daí a necessidade de se atentar para a abertura e disponibilidade das pessoas, para a capacidade da escuta sensível, para a competência relacional dos pesquisadores. Estas capacidades estão, de fato, para além de saberes disciplinares.

\title{
50 trabalho interdisciplinar em Ciências das Religiões
}

A frase "as Ciências da Religião no Brasil surgiram no tempo da interdisciplinaridade" (FERREIRA; SENRA, 2012, p. 266) sintetiza bem o contexto histórico de efervescência do debate sobre a questão no país, nos anos 70, coincidindo com a estruturação dos primeiros cursos de pós-graduação da área.

Desde então, é possível registrar que houve inicialmente uma compreensão de que a interdisciplinaridade seria realizada apenas pelo esforço de especialistas para aplicar o seu conhecimento específico, adquirido em uma disciplina, na área, o que de fato não configura uma prática interdisciplinar. $\mathrm{O}$ fato de um historiador estudar historicamente uma religião não significa um trabalho interdisciplinar por si só - a aplicação do método de um campo de conhecimento ao estudo da religião não o torna interdisciplinar. O estudo historiográfico da religião é um estudo do 
campo da História, assim como o estudo de bases psicológicas e comportamentais de religiosos é um estudo do campo da Psicologia.

Assim como acontece nas Ciências da Informação e na Educação, a interdisciplinaridade tende a ser confundida, nas Ciências das Religiões, como a incorporação das particulares disciplinares em termos teóricos e metodológicos trazidas pelos pesquisadores desde os seus lugares acadêmicos de origem. Ao migrarem, eles levam consigo a potencialidade da interdisciplinaridade, que é condição necessária, mas não suficiente para que ela floresça. A assimilação dos aportes conceituais e metodológicos de outras disciplinas tende a caracterizar o campo como eclético e não interdisciplinar. A superação deste estado se dá na afirmação da memória do campo de conhecimento: quanto mais assentado e claro estiver esta especificidade, mais condições existirão para a instauração de relações interdisciplinares (BICALHO; OLIVEIRA, 2011).

A existência de um conjunto de pesquisadores de diferentes disciplinas científicas em uma unidade organizacional e administrativa é o primeiro passo para a constituição de grupos interdisciplinares. Sem esta base inicial não é possível a interdisciplinaridade - as formações diversas dos pesquisadores é, portanto, condição necessária mas não suficiente. Além disso, devemos registrar que quando se trata do campo das Ciências das Religiões, a existência de diferentes disciplinas "favorece uma compreensão mais dinâmica e aberta sobre o objeto em questão, o fato religioso. Essa demarcação epistêmica permite que se abram sempre novas possibilidades analíticas sobre o objeto a ser conhecido.” (FERREIRA; SENRA, 2012, p. 263).

Cabe destacar que a organização de debates é insuficiente para a afirmação da existência da interdisciplinaridade, apesar de ser necessária para o desenvolvimento deste tipo de trabalho. A interdisciplinaridade é mais exigente do que isso, é "um modo de pensar a realidade pelo sujeito pesquisador individual ou coletivo (...) não é uma junção, mas outra forma de produção do conhecimento, que se vale dos saberes e olhares disciplinares em uma e mesma composição teórica” 
(FARIA, 2015, p. 133). E neste sentido, a constituição de grupos de pesquisa e criação de redes de investigação é fundamental.

Por outro lado, a interdisciplinaridade, como método na organização do trabalho acadêmico "não pode escamotear o desafio de pensar a epistemologia própria das ciências da religião, pela simples razão que não pode haver interdisciplinaridade sem disciplinaridade." (FARIA, 2018, p. 1337). A disciplina se caracteriza pela existência de identidade própria, de conhecimentos e métodos voltados para a compreensão de um fenômeno, no caso, o fenômeno religioso. Nesses termos, a questão da interdisciplinaridade supõe o diálogo de diferentes disciplinas sobre o fenômeno religioso, inclusive o olhar disciplinar das Ciências das Religiões.

As Ciências das Religiões se ocupam do que é essencialmente a religião. Nesses termos, cabe retomar a clássica reflexão de Cornelis Petrus Tiele, feita em 1897. Para o autor, a compreensão do fenômeno religioso decorre necessariamente de uma investigação sobre as

manifestações da mente humana em palavras, atos, costumes e instituições que testemunham a crença do homem no sobre-humano, e servem para conduzi-lo na relação com ele. Nossa investigação revelará o fundamento desses fenômenos geralmente chamados de religiosos [...] $\mathrm{O}$ objetivo da nossa ciência não é o próprio sobre-humano, mas a religião baseada na crença no sobre-humano; e a tarefa de investigar a religião como um fenômeno histórico-psicológico, social e totalmente humano, sem dúvida, pertence ao domínio da ciência. (TIELE, 2018, p. 218-219).

O campo de pesquisa das Ciências das Religiões é extenso e variado comporta religiões de todo o mundo em seus diferentes estágios de desenvolvimento, inclui fenômenos religiosos atuais, recriações e também os que estão mortos. Estuda-se a religião a partir da "mente humana, que não se revela em nada tão completamente como neles." (TIELE, 2018, p. 219). Para Tiele, o objetivo deste campo científico é "sujeitar a religião, como um fenômeno humano e, portanto, histórico e psicológico, a uma investigação sem preconceitos, a fim de verificar a forma como ela surge e cresce, quais são os seus elementos essenciais e, por fim, compreendê-la.” (2018, p. 219). 
Este é um ponto importante na reflexão sobre o tema. O campo das Ciências das Religiões possui uma especificidade e é a partir dela, e com ela, que se pode adentrar no debate com outras ciências, em busca de perspectivas interdisciplinares sobre um determinado fenômeno. Tal especificidade se refere justamente ao estudo da religião enquanto fenômeno humano. Sem a afirmação da singularidade das Ciências das Religiões não há possibilidade de debate interdisciplinar.

Considerando as reflexões feitas até então, podemos nos referir às Ciências das Religiões como uma área de conhecimento com vocação interdisciplinar, que traz no seu interior uma potencialidade metacientífica, se tomarmos como científico o disciplinar. Isto ocorre tendo em vista que "a própria complexidade do fato religioso parece exigir estudos interdisciplinares." (FERREIRA; SENRA, 2012, p. 259). Esta complexidade registrada pelos autores está relacionada, de forma especial, à compreensão de que o fato religioso está situado no âmbito da cultura: “As Ciências da Religião estão circunscritas no mundo da cultura e demandam, nesse cenário, abordagens interdisciplinares.” (FERREIRA; SENRA, 2012, p. 264).

Neste sentido, concordamos com a afirmação de que a tendência da

pesquisa do fato religioso no Brasil se vê orientada por procedimentos que conduzem $o$ pesquisador a fazer inferências críticas, realizar demonstrações, construir sínteses e análises, bem como construir quadros compreensivos que utilizem arcabouços teórico-metodológicos de cunho científico em perspectiva interdisciplinar. Esse fazer científico procura compreender o fato religioso e exige situá-lo no espaço cultural. As Ciências da Religião estão circunscritas no mundo da cultura e demandam, nesse cenário, abordagens interdisciplinares. (FERREIRA; SENRA, p. 263).

Ao ser identificada com (re)criação de sentidos, compreensões e explicações do mundo, a cultura não se reduz a um conjunto de informações assimilados acriticamente pelos sujeitos. As expressões culturais carregam no seu bojo novas formas de socialização e de saber, que na atualidade são gestadas no interior da reestruturação capitalista. Neste contexto, as Ciências das Religiões impõe-se como 
um campo explicativo de um espaço cultural formado por múltiplas experiências, que constituem o tecido da vida diária das pessoas. Tais experiências precisam ser revisitadas do ponto de vista acadêmico e científico, para alcançarmos novas compreensões dos fenômenos.

Compreender o fenômeno religioso em suas expressões simbólicas, materializadas nos modos de vida, trabalho, formas de ser, sentir e agir, em uma palavra, culturalmente, significa colocar como exigência um olhar interdisciplinar, pela própria qualidade dos elementos que o constituem. A interdisciplinaridade não significa, portanto, uma opção e sim uma condição para o desenvolvimento teórico e metodológico das Ciências das Religiões.

\section{A interdisciplinaridade na origem das Ciências das Religiões}

Adotamos como origem das Ciências das Religiões, o trabalho pioneiro feito por Max Muller, no século XIX. Uma série de conferências, que foram reunidas em um volume intitulado Chips from a German Wokshop (1867), e posteriormente a obra Introduction to the Science of Religion (1873), que também são conferências ministradas no Royal Institution em Londres, constituem o que entendemos como o fundamento de nosso campo, historicamente considerando. Muller toma como ponto de partida, para o estabelecimento da Ciência da Religião, a Ciência da Linguagem, que foi por ele mesmo idealizada, tendo como método a filologia comparada². A palavra-chave, tanto de uma ciência quanto da outra, é portanto a comparação. Diz Müller:

Pessoas perguntam: O que é ganho por comparação? - Ora, todo conhecimento superior é adquirido por comparação e repousa na comparação. Se é dito que o caráter da pesquisa científica, em nossa era, é preeminentemente comparativo, isso realmente significa que nossas

\footnotetext{
2 "You may have observed that I always took it for granted that the science of language, which is best known in this country by the name of comparative philology, is one of the physical sciences, and that therefore its method ought to be the same as that which has been followed with so much success in botany, geology, anatomy, and other branches of the study of nature" (Muller, 1862, p.20). "Podeis ter observado que eu sempre tive como certo que a ciência da linguagem, que é mais conhecida neste país pelo nome de filologia comparativa, é uma das ciências físicas, e que, portanto, seu método deve ser o mesmo que aquele que tem sido seguido com tanto sucesso na botânica, geologia, anatomia e outros ramos do estudo da natureza" (tradução nossa).
} 
pesquisas agora se baseiam na evidência mais ampla que pode ser obtida, nas mais amplas induções que podem ser compreendidas pela mente humana. (MÜLLER, 1873, p. 11-12, tradução nossa). 3

O paradoxo de Goethe ("Quem conhece uma língua, não conhece nenhuma”) é então transposto por Muller (1873, p. 16) para a religião: "Quem conhece apenas uma, não conhece nenhuma" (tradução nossa). $4 \mathrm{O}$ paradoxo se desfaz, segundo Muller, pela compreensão do duplo sentido do verbo to know: primeiro, "ser destro em"; e, segundo, "saber”. Assim, quem é hábil, destro e capaz de seguir sua própria religião, nem sempre conhece, com a devida profundidade, seus aspectos doutrinários, internos e externos5. Deduz-se daqui um duplo sentido para o termo "religião": de um lado, o "saber" a doutrina, e, de outro, o "vivenciar" a doutrina, por meio de uma faculdade que ele denomina de faculty of faith, faculdade de fé, por analogia com faculty of language. Equipara-se a faculdade de fé, explicada como "faculdade de perceber o infinito" (MULLER, 1873, p. 18. Tradução nossa) ${ }^{6}$ com as demais faculdades: a sensorial (o sentido) e a racional (a razão). A faculdade de fé é

um poder independente do sentido e da razão, um poder, de certo modo, em contradição com o sentido e a razão, mas ainda assim um poder muito real, que se manteve desde o começo do mundo, nem o sentido nem a razão sendo capazes de superá-lo, enquanto só ele é capaz de superar a razão e o sentido. (MULLER, 1873, p. 18, tradução nossa)7.

Aproxima-se, segundo nosso entendimento, o conceito de Muller com a compreensão moderna de Espiritualidade. Retomando então o raciocínio do autor, os dois sentidos do termo "religião" correspondem, em certa medida, à divisão que Muller (1873, p. 21) propõe para a Ciência da Religião: Teologia Comparativa ou Comparada, que lida com as formas históricas da religião, e Teologia Teorética, que

\footnotetext{
${ }^{3}$ People ask, What is gained by comparison? - Why, all highter knowledge is acquired by comparison, and rests on comparison. If it is said that the character of scientific research in our age is pre-eminetly comparative, this really means that our researches are now based on the widest evidence that can be obtained, on the broadest inductions that can be grasped by the human mind.

4 "He who knows one, knows none".

${ }^{5}$ Igualmente, quem fala fluentemente uma língua, nem sempre conhece fonologia, morfologia, sintaxe, semântica, etc.

6 "faculty of perceiving the Infinite".

7 "a power independent of sense and reason, a power in a certain sense contradicted by sense and reason, but yet a very real power, which has held its own from the beginning of the world, neither sense nor reason being able to overcome it, while it alone is able to overcome both reason and sense.
} 
explica as condições, internas e externas, sob as quais a religião é possível, ou seja, a filosofia da religião. Nesta obra, que estamos acompanhando, Introduction to the Science of Religion, Muller (1873, p. 34) se ocupará exclusivamente da Teologia Comparativa:"Uma Ciência da Religião, baseada em uma comparação imparcial e verdadeiramente científica de todas, ou de todos os eventos, das religiões mais importantes da humanidade, é agora apenas uma questão de tempo" (tradução nossa). 8

Dados estes pressupostos da obra pioneira de Max Muller, o ponto que queremos historicamente destacar é o seguinte: na recém-nascida Ciência da Religião, na sua parte que trata da Teologia Comparativa, o método empregado pelo autor é também interdisciplinar. Deste modo, a comparação que é feita entre duas ou mais religiões permite não apenas identificar aquilo que é comum entre elas e, por sua vez, o que lhes é diferenciado, mas sim encontrar coisas novas, que estão no espaço entre as religiões, espaço este interdisciplinar, por definição. Esta é a contribuição mais original para o conhecimento das religiões, sem desconsiderar evidentemente o aprofundamento dos temas já conhecidos, oferecidos igualmente pela possibilidade metodológica.

Em síntese, a Teologia Teorética permite conhecer a religião A; a mesma disciplina permite conhecer a religião B. Por outro lado, a Teologia Comparativa, aplicada às religiões $\mathrm{A}$ e $\mathrm{B}$, permite conhecer $\mathrm{C}$, que existe potencialmente em $\mathrm{A} \mathrm{e}$ B, mas explicitamente só aparece pela comparação. Vejamos o diagrama, em que D representa o que é comum e E1 e E2 o que são diferentes. O método filológico, proposto por Muller, permite encontrar C.

\footnotetext{
${ }^{8}$ A Science of Religion, based on an impartial and truly scientific comparison of all, or at all events, of the most important religions of mankind, is now only a question of time
} 


\section{Ciências das Religiões}

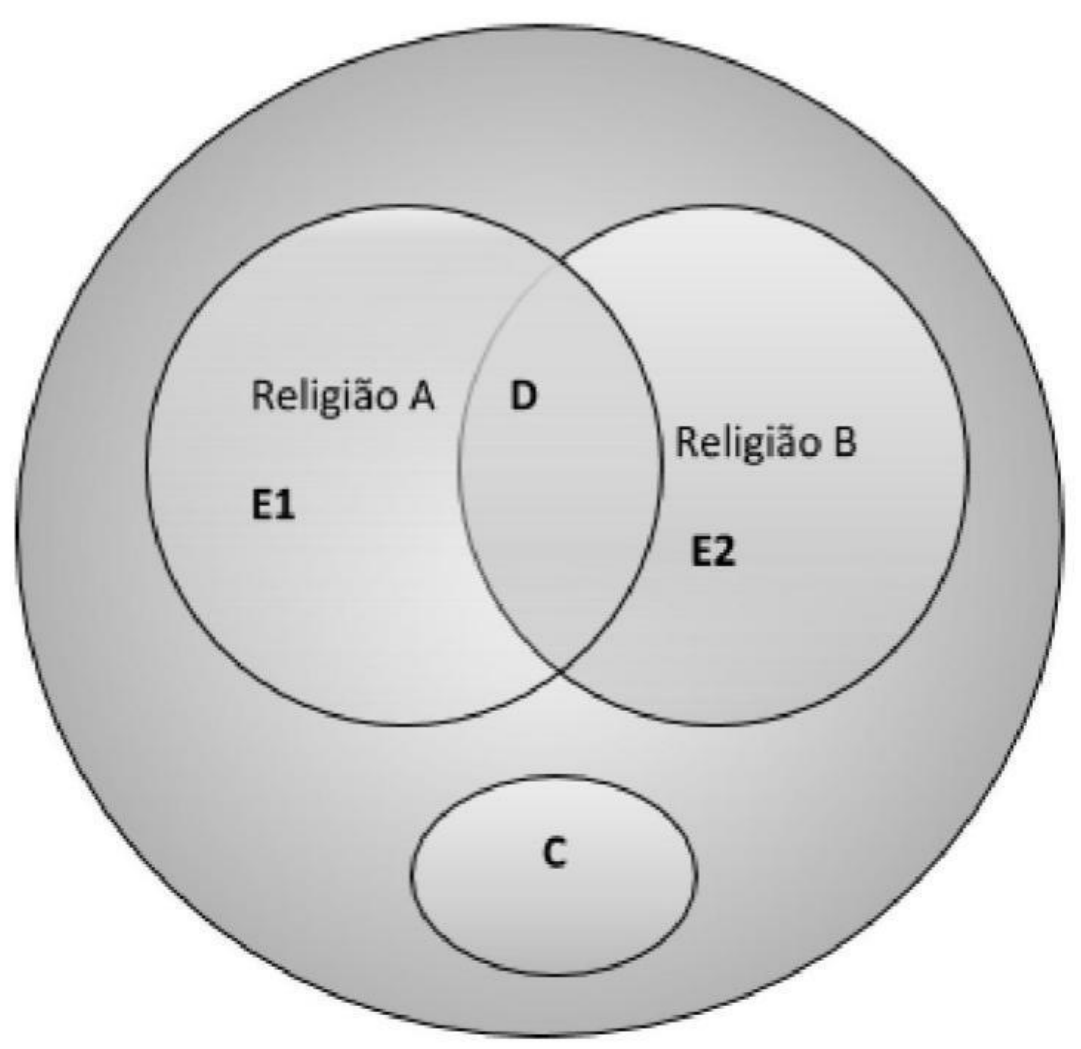

Fonte: Elaborado pelos autores.

Vejamos uma aplicação prática do método, sob o olhar interdisciplinar, seguindo um exemplo desenvolvido pelo autor:

Se lemos, por exemplo, que depois que o primeiro homem foi criado, uma de suas costelas foi retirada, e essa costela se transformou em uma mulher, todo estudante de língua antiga vê imediatamente que esse relato não deve ser tomado em seu sentido desnudo e literal. (MULLER, 1873, p. 45, tradução nossa). 9

A questão que aqui é posta para o método filológico é: como entender o termo "costela", já sabendo das limitações do sentido literal?

\footnotetext{
${ }^{9}$ If we read, for instance, that after the first man was created, one of his ribs was taken out, and that rib made into a woman, every student of ancient language sees at once that this account must not be taken in its bare, literal sense.
} 


\section{Diz Muller:}

Na antiga língua do Veda, osso, sangue, respiração, todos são destinados a transmitir mais do que devemos chamar de seu significado material; mas, com o passar do tempo, o sânscrito âtman, que significa originalmente respiração, reduziu-se em um mero pronome e passou a significar "eu". O mesmo se aplica ao 'etzem hebraico. Originalmente significando osso, veio a ser usado, por fim, como um mero adjetivo pronominal, no sentido de "eu" ou “mesmo". (MULLER, 1873, p. 46, tradução nossa). ${ }^{10}$

A partir desta comparação, Muller diz que Adão poderia ter dito à Eva: “Tu és o mesmo que eu sou”, tal pensamento seria expresso no hebraico antigo por: "Tu és osso do meu osso e carne da minha carne” (MULLER, 1873, p. 47, tradução nossa).11 Tal é, em conclusão, o resultado obtido pelo método: o termo "costela" significa “o mesmo”, na passagem em estudo, isto é, um elemento do judaísmo sendo explicado a partir do hinduísmo.

Este exemplo pontual quis mostrar uma das potencialidades advindas do método filológico, que é a interdisciplinaridade. A comparação acima referida não se limita, evidentemente, a religiões como um todo, mas abrange narrativas, personagens, lendas, mitos, ritos e tudo o mais que se queira pôr em evidência. De fato, o próprio conceito de religião, como organização institucionalizada, nem sempre pode ser posto para os povos mais antigos ou para as sociedades tradicionais. Por fim, cabe destacar que tal foi a crença de Max Muller na possibilidade de diálogos que ele editou a imensa coleção The Sacred Books of the East, que contém cinquenta volumes, abarcando as principais obras das doutrinas do oriente, traduzidas dos originais por especialistas, a partir do sânscrito, do chinês, do páli, do persa e do árabe, para que o estudioso pudesse ter uma base segura de reflexão.

\footnotetext{
${ }^{10}$ In the ancient language of the Veda, bone, blood, breath, are all meant to convey more than what we should call their material meaning; but in course of time, the Sanskrit âtman, meaning originally breath, dwindled away into a mere pronoun, and came to mean self. The sameappliestotheHebrew'etzem. Originally meaning bone, it came to be used at last as a mere pronominal adjective, in the sense of self or same.

${ }_{11}$ "Thou art the same as I am", such a thought would in ancient Hebrew be expressed by: "Thou art bone of my bone, and flesh of my flesh".
} 


\section{Conclusões}

As Ciências das Religiões constituem um campo propício para o desenvolvimento de práticas de ensino e de pesquisa interdisciplinares pela natureza do seu objeto, como o exemplo pontual de Max Muller quis demonstrar. Sua vocação remete para a complexidade de um fato - o fato religioso -, que é atravessado por um conjunto de expressões culturais que se manifestam na vida diária dos sujeitos, que interferem e moldam comportamentos e ações.

Neste sentido, apreender o objeto nas Ciências das Religiões exige do pesquisador uma abertura para a sua complexidade, que está para além da prática disciplinar. Além disso, coloca como exigência um conjunto de novas competências, necessárias para a realização do trabalho coletivo.

Ao final deste artigo, destacamos quatro pontos que julgamos necessários para a criação e fortalecimento de práticas interdisciplinares na área das Ciências das Religiões:

a. O fortalecimento dos grupos de pesquisa e de redes de investigação. Grupos e redes são unidades acadêmicas flexíveis que permitem o exercício da criatividade que permitem a convivência produtiva de seniores e jovens pesquisadores que, em colaboração e de forma solidária, produzem novos conhecimentos e novas demandas para a área.

b. A criação de espaços institucionais que fomentem a interdisciplinaridade. Neste sentido, consideramos que a constituição de núcleos de pesquisa possa ser um primeiro passo neste sentido, podendo apontar a médio prazo para a organização de cursos de pós-graduação;

c. A instituição de espaços criativos de convivência. Os pesquisadores precisam se conhecer academicamente envoltos por uma ambiência afetiva, como por exemplo, em cafés literários. O importante é que sejam espaços não burocratizados onde se possa conversar coletivamente sobre temas de interesse da comunidade acadêmica. 
d. Fomento a debates sobre o campo de conhecimento das Ciências das Religiões, a fim de buscar novos consensos teóricos e metodológicos na comunidade acadêmica, a partir das novas descobertas realizadas.

Estamos diante de muitos desafios. Entretanto, a consciência de que o avanço e o fortalecimento estão na constituição do sujeito coletivo resulta tranquilizador. Caminhar acompanhado não garante alcançar o objetivo estabelecido, mas certamente nos permite refletir com mais qualidade sobre a trajetória.

\section{REFERÊNCIAS}

ALVARENGA, Augusta Thereza de; ALVAREZ, Aparecida Magali de Souza; SOMMERMAN, Américo; PHILIPPI JÚNIOR, Arlindo. Interdisciplinaridade e transdisciplinaridade nas tramas da complexidade e desafios aos processos investigativos. In: PHILIPPI JÚNIOR, Arlindo; FERNANDES, Valdir (ed.). Práticas da interdisciplinaridade no ensino e pesquisa. Barueri: Manole, 2015. cap. 2, p. 37-90.

ARANA, Lizgrace Llano; ESCOBAR, Miriam Gutiérrez; RODRÍGUEZ, AddysStable; MARTÍNEZ, María Cristina Núñez; RIVERO, Rosa María Masó; RIVERO, Bárbara Rojas. La interdisciplinariedad: una necesidad contemporánea para favorecer el proceso de enseñanza aprendizaje. Medisur, Cienfuegos, v. 14, n. 3, abr.-jun. 2016.

BICALHO, Lucinéia; OLIVEIRA, Marlene de. A teoria e a prática da interdisciplinaridade em ciência da informação. Perspectivas em Ciência da Informação, Belo Horizonte, v. 16, n. 13, p. 47-74, jul.-set. 2011. Disponível em:

http://www.scielo.br/pdf/pci/v16n3/o4.pdf. Acesso em: 11 nov. 2020.

DURHAM, Alan Mitchell; SETÚBAL, João Carlos; BARRERA, Júnior. Interdisciplinaridade em ação na pesquisa e pós-graduação em bioinformática. In: PHILIPPI JÚNIOR, Arlindo; FERNANDES, Valdir (ed.). Práticas da interdisciplinaridade no ensino e pesquisa. Barueri: Manole, 2015. cap. 20, p. 610642.

FARIA, José Henrique de. Epistemologia crítica, metodologia e interdisciplinaridade. In: PHILIPPI JÚNIOR, Arlindo; FERNANDES, Valdir (ed.). Práticas da interdisciplinaridade no ensino e pesquisa. Barueri: Manole, 2015. cap. 3, p. 91-136.

FARIA, Paulo Antônio Couto. Ciências da religião e teologia: evolução de uma relação. Horizonte, Belo Horizonte, v. 16, n. 51, p. 1324-1350, set.-dez. 2018.

FERREIRA, Amauri Carlos Ferreira; SENRA, Flávio. Tendência interdisciplinar das Ciências da Religião no Brasil. O debate epistemológico em torno da interdisciplinaridade e o paralelo com a constituição da área no país. Numen: revista de estudos e pesquisa da religião, Juiz de Fora, v. 15, n. 2, p. 249-269, 2012. 
FREIRE, Paulo. Pedagogia da autonomia: saberes necessários à prática educativa. São Paulo: Paz e Terra, 2018.

GOMEZ, Maria Nelida Gonzalez de. Da interdisciplinaridade às experiências de responsabilidades distribuídas. RECIIS: revista eletrônica de comunicação, informação e inovação em saúde, Rio de Janeiro, v. 10, n. 2, p. 1-3, abr./jun. 2016.

GONÇALVES, Elisa Pereira. Educação e o processo de mundialização da cultura.

Comunicações, Piracicaba, v. 3, n. 1, P. 75-77, 1996.

MARTÍNEZ, Amnia Yudet Ortega; POMPA, Félix Díaz; PÉREZ, Carlos Miguel Martínez; CARBONELL, Eduviges Mingui. La educación desde el enfoque interdisciplinar. Un reto para la educación de adultos. Revista de Estudios y Experiencia en Educación, v. 13, n. 25, p. 167-190, enero-jul. 2014.

MIELE, Neide; POSSEBON, Fabricio. Numen: revista de estudos e pesquisa da religião, Juiz de Fora, v. 15, n. 2, p. 403-431, jun.-dez. 2012.

MULLER, F. Max. Chips from a German workshop. London: Longmans,1867.

MULLER, F. Max. Introduction to science of religion. Four lectures delivered at the Royal Institution with two essays on false analogies, and the philosophy of mythology. London: Longmans, 1873.

MULLER, F. Max. Lectures on the science of language. Delivered at the Royal Institution of Great Britain in April, May, and June, 1861. Nova York: Charles Scribner, 1862.

MULLER, F. Max. Mitologia comparada. Barcelona: Vision Libros, s.d.

NEVES, Carmen Moreira de Castro. Formação de professores da educação básica: a interdisciplinaridade necessária. In: PHILIPPI JÚNIOR, Arlindo; FERNANDES, Valdir (ed.). Práticas da interdisciplinaridade no ensino e pesquisa. Barueri: Manole, 2015. cap. 15 , p. 471-502.

POMBO, Olga; GUIMARAES, Henrique Manuel; LEVY, Teresa. Interdisciplinaridade: antologia. Porto: Campo das Letras, 2006.

RAYNAUT, Claude. Interdisciplinaridade na pesquisa: lições de uma experiência concreta. In: PHILIPPI JÚNIOR, Arlindo; FERNANDES, Valdir (ed.). Práticas da interdisciplinaridade no ensino e pesquisa. Barueri: Manole, 2015. cap. 1, p. 3-36.

SOBRAL, Maria do Carmo; SAMPAIO, Carlos Alberto Cioce; FERNANDES, Valdir; PHILIPPI JÚNIOR, Arlindo. Práticas interdisciplinares no campo das ciências ambientais. In: PHILIPPI JÚNIOR, Arlindo; FERNANDES, Valdir (ed.). Práticas da interdisciplinaridade no ensino e pesquisa. Barueri: Manole, 2015. cap. 16, p. 503550 . 
SOMMERMAN, Américo. Alguns eventos e documentos de referência no campo da transdisciplinaridade. In: SANTOS, Akiko; SOMMERMAN, Américo (org.). Ensino disciplinar e transdisciplinar: uma coexistência necessária. Rio de Janeiro: Wak Editora, 2014. p. 19-65. cap. 1, p. 19-66.

SOMMERMAN, Américo. Objeto, método e finalidade da interdisciplinaridade. In: PHILIPPI JÚNIOR, Arlindo; FERNANDES, Valdir (ed.). Práticas da interdisciplinaridade no ensino e pesquisa. Barueri: Manole, 2015. cap. 5, p. 165212.

TIELE, Cornelis Petrus. Concepção, objetivo e método da Ciência da Religião. Rever, São Paulo, v. 18, n. 3, p. 217-228, set.-dez. 2018. 